\title{
Challenges of monolingual intercultural communication in the context of the Languages Connect strategy
}

\author{
Liam Murray \& Marta Giralt \\ University of Limerick \\ Liam.Murray@ul.ie\& Marta.Giralt@ul.ie
}

\begin{abstract}
The new national language strategy (Languages Connect) for Ireland has finally highlighted the importance of language learning for the economic, social and cultural development of the country. Inherent to this strategy is the demand for not only multilingual graduates but interculturally competent graduates. Ireland has been becoming increasingly culturally diverse for many years now, and so our contexts of work and interactions have become multilingual as well as multicultural. Yet many of our students remain limited in their acquisition and exposure to foreign language(s) and culture(s).
\end{abstract}

Previously we reported (Murray \& Giralt, 2018) how our pedagogical content and practices are insufficient in addressing the current linguistic and intercultural competence (IC) needs of language specialist graduates. Using a mixed-methods approach, our recent data $(n=235)$ has emerged from both non-specialist and specialist language students. The analysis of this data reveals a number of issues, particularly with problems arising from monolingual intercultural communications due to English being the dominant lingua franca. We have major challenges in motivating monolingual students to learn another language. The dangers arising from this monolingualism are self-evident, (see, for example: https://www.llas.ac.uk/700reasons.html), the solutions less so. This article explores this perplexing scenario and aims to open a dialogue on this subject, offering some recommendations and potential solutions, within the context of the Languages Connect strategy. 
Keywords: Languages Connect; Intercultural Competence; lingua franca English; multilingualism

\section{Introduction}

Nowadays, it appears almost redundant to talk about a globalised and multicultural world as we all live in, read about and experience such a world. Globalisation and multiculturalism may claim to be a real and true reflection of our society, workplace and educational institutions. However, it is also true that some degree of social homophily still governs the way we relate and interact with others (Millard, 2017). This phenomenon was first identified over sixty years ago by Lazarsfeld and Merton (1954) and more recently many aspects of this evolving phenomenon have been heightened (or exacerbated) by our online interactions within social networks (McPherson, SmithLovin \& Cook, 2001; Currarini, Matheson, \& Vega-Redondo, 2016).

At the same time, internationalisation appears as a process and strategy in most Third Level institutions, with the Erasmus experience and the period abroad for students still remaining as the main practices identified with it (De Wit, 2016). We regard "global citizenship" as one of the outcomes that our graduates need to achieve after finishing their studies (Kramsch, 2019). This global competence should equip them to work, lead socially responsible lives and be interculturally capable of interacting with people from other cultures with a certain degree of civic engagement (Morais \& Ogden 2011, p. 449). 'As the notion of global citizenship has become part of the internationalisation discourse in higher education around the world' (Deardorff \& Jones 2012, p. 295), we feel a need to scrutinise, at a local institutional level, those pedagogical practices currently in place to enhance and provide the means for our students to develop interculturally and finally become competent global citizens. Looking closely at a departmental level here at the University of Limerick, Ireland, we observed and identified that our undergraduates on the Applied Languages programme receive little or no formal training in Intercultural Communicative Competence (ICC), which exists as a focussed extension of Intercultural Competence (IC). Furthermore, we would assert that Applied Language students and language specialists need to graduate with a high linguistic competence in the additional language/s they are studying, and with a deep appreciation 
of the target culture(s). However, intercultural training and knowledge transfer currently do not seem to occur to a substantial degree.

Additionally, non-language specialists or students who have not formally studied or are not studying any language-other than the compulsory study of Gaeilge in the first two levels of the Irish education system - are also expected by future employers (Wyburd, 2018) to develop their IC during their time in third level education. More and more employers are demanding that they acquire the necessary skills to make them competitive and competent graduates performing efficiently in multicultural environments (Griffith et al., 2016). With these expectations in mind, it is worth noting here that monolingual English speaker (MES) graduates (Jenkins 2015, p. 56) may find themselves at a greater disadvantage in their future career opportunities as they have had very few opportunities to raise their intercultural awareness. Graddol (2006) goes further in pointing out the non-competitiveness of MES in future workplaces, emphasising that they will carry with them an inherent disadvantage compared to their multilingual colleagues elsewhere. Indeed, recent research has convincingly proven the value of language skills to the Irish economy itself (Schroedler, 2018).

In the context of the Irish Government's recent Languages Connect strategy (Department of Education and Skills, 2017), this article seeks to explore the crucial place that intercultural communication and IC occupies for our graduates in Ireland. In so doing, we will present data that evidences the levels of cultural awareness and IC that language specialists, non-specialists and selfidentified MES undergraduates achieve whilst attending our institution. Finally, we will offer some recommendations which draw upon and extend the Languages Connect strategy in attempting to resolve these imbalances in IC and ICC amongst our students.

\section{ICC \& Competitive Advantages For Global Employability}

As mentioned above, the world of employment is interconnected and globalised and many professional environments where citizens need to navigate are already multicultural and multilingual (Sherman \& Strubell, 2013). Unsurprisingly, there are few professional working 
contexts which have remained monocultural. These factors are translated into a higher demand for interculturally competent graduates (Griffith et al., 2016) who will need the skills to perceive, understand and interact effectively and satisfactorily in any intercultural communication setting. The ability to communicate appropriately and productively with people of other cultures has long been carefully approached and promoted by higher education institutions and particularly in relation to the future employability of students (Wyburd, 2018). Research has shown how the focus is on the development of graduates who are able to interact across different cultures as companions, community members and global citizens in order to acquire values and benefits that go beyond employment and monetary gain (Haigh \& Clifford, 2010; Maguth \& Hilburn, 2015). By way of responding to this, many firms and companies today have formalised policies and strategies focused on workplace linguistic diversity (Angouri, 2014), superdiversity (Nekvapil \& Sherman, 2018), inclusion and intercultural awareness stressing the importance and influence those factors have, among other things, on internationalisation, employee satisfaction, innovation and productivity (Reinmoeller and Van Baardwijk 2005; Demangeot, C., et al. 2013). Acquiring IC is of course an iterative process where actors from multicultural educational environments and marketplaces become culturally competent after passing through the different stages of an intercultural competency development based on experiences, reflections, conceptualisations and experimentation (Bennet, 2009; Gregersen-Hermans \& Pusch, 2012; Demangeot, C., et al. 2013). In addition to this, research also reveals how candidates with language skills are more readily recruited by international companies, as the development of language competencies tends to be linked with the development of a range of other skills (Nuffield Languages Inquiry, 2000) and professional competence (Vaara, et al., 2005). These skills may also include the ability to communicate via a variety of online media, as other researchers have highlighted when attempting to extend the notion of ICC (Orsini-Jones \& Lee 2018, p. 7). Welch and Welch relate how international firms should themselves be developing their own language strategy (with no actual stated awareness of IC nor ICC) as they argue that: "A key aspect is the role of management in shifting the firm from a reactive to a more proactive stance on language strategy" $(2017$, p. 1). 
In addition to governmental measures such as the Languages Connect strategy and international business language strategies, we also note that online Cultural and Intercultural Literacy (Belshaw, 2012) has been identified as a key digital skill. Such a skill effectively emerges from the learner (or, of course, citizen) being an active participant in online spaces. Interacting cogently and constructively with people from other cultures has taken on even greater importance in our global world (Hockly, Dudeney \& Pegrum, 2014, p. 34). The globalised world demands more contact among the members that live in it, as much in the social as in the professional environment, a fact that is crucial during students' time in college: "As learning projects become more globalised, and more exchange based, learning how to interact with other cultures is key - not only to the successful completion of a given project, but beyond it, with wider implications in the professional sphere" (Hockly, Dudeney \& Pegrum, 2014, p. 76).

\subsection{Intercultural Competencies: Different Conceptual Models}

Many researchers have explored, debated and proposed various conceptual models of both IC and ICC. Here, we would enumerate the more relevant models as they apply to our context. Bennett (1986) and later Witte (2014) offer an introductory model describing various intercultural sensitivity stages, which range from ethnocentric stages such as: denial, defense and minimisation, to ethnorelative stages such as: acceptance, adaptation and final integration. This developmental model described by Bennett (1986) is presented as linear, which could infer that the process of culture learning also follows a continuous development framework. However, Bennett (2004) later recognises that the model is not progressive and that learners may skip certain stages. Deardorff's (2008) process model of IC also highlights the notion that an individual may follow a non-linear path in the journey to acquire IC. Yet, whilst acknowledging the continuing and lifelong features of this process, she does contend that: "one never reaches the pinnacle of intercultural competence", (p. 39). Byram also proposes a developmental model which makes a clear distinction between IC and ICC: "In the first case, individuals have the ability to interact in their own language with people from another country and culture. On the other hand, someone with Intercultural Communicative Competence is able to interact with people from another country and culture in a foreign language", (1997, pp. 70-1). Perhaps the most widely known amongst Applied Linguistics 
researchers, Byram's model of ICC comprises linguistic, sociolinguistic, discourse and intercultural components. It is made up of five savoirs (or cognitive elements) which cover: interpreting/relating skills; discovery/interaction skills; knowledge (of social groups in one's own or other cultures and a general interaction process); attitudes (curiosity and openness); and finally, a critical cultural awareness, (Byram, Gribkova \& Starkey, 2002). Other definitions and models of IC \& ICC also include notions such as the importance of cultural differences (Chen \& Starosta 2006, p. 357) and global citizenship (Kramsch, 2019).

As a tentative conclusion to this brief overview of IC \& ICC, it is worth noting that these models are somewhat fungible and the concept itself remains "slippery" in definition (Dervin, 2012) and continues to evolve. As an example of this continuity and expansion of this topic, the more recently devised concept of ICCC (Intercultural Cyberpragmatic Communicative Competence) as proposed by Orsini-Jones and Lee (2018) may be explored. This effectively and persuasively broadens the definition of ICC to include various elements dealing with, inter alia, successful online communication for language acquisition within telecollaborative activities.

\section{The Irish National Languages Connect strategy highlighting IC Awareness and Competence}

On December 4th 2017, Minister Bruton, the then Irish Minister of Education and Skills, launched the Languages Connect strategy prioritising the teaching of foreign languages (Department of Education and Skills, 2017). The 40 page document of 14,589 words, uses the term 'intercultural' 9 times, from which we have extracted several quotations that highlight the narrow line between multilingualism and IC. The document recognises the enhancement and development of IC through multilingualism: "The need to raise awareness in society at large of the benefits of varied language capacity for intercultural understanding, for positive citizenship and for job and career opportunities" (Languages Connect - Ireland's Strategy for Foreign Languages in Education 2017 2026, p.15) [Our italics].

It is noted here that this document represents a strategy and not an actual governmental policy. However, the strategy should be welcomed by language professionals as it points out the need for 
language proficiency and intercultural skills among graduates in the professional sphere:

\begin{abstract}
“Ireland's position as a small country with a globalised economy is an impetus for employers and companies to promote language proficiency and intercultural skills among their employees. These graduates can not only provide language and intercultural awareness expertise for their employer, but also an opportunity for other employees to interact through another language in a workplace setting" (Ibid. p.17). [Our italics].
\end{abstract}

Moreover, the document encourages the use of languages in everyday life to enhance and develop IC, which at the same time can foster interest and curiosity for learning other languages: "In using languages in daily life, positive attitudes towards, and appreciation of, cultural diversity can be fostered, as well as an interest and curiosity in learning further languages and intercultural communication" (Ibid. p.36). As multilingualism is promoted, in the context of the Languages Connect strategy, it should surely be applauded that this challenges-especially in third level education - the global dominance of English and its status as the primary lingua franca. Some researchers have claimed that a global English language hegemony will continue for at least another half-century (Burns \& Coffin, 2013). Yet, amongst the many inherent erroneous beliefs supporting English as a lingua franca, is the mistaken belief that 'English is enough', and this may result in complacency and a lack of motivation to learn other languages (Demont-Heinrich, 2009). The dangers of such complacency and lack of engagement with foreign language acquisition and promotion have been widely recognised in Britain for quite some time (Lanvers \& Coleman, 2017). If such a situation is allowed to continue anywhere, then the repercussions may go beyond these intercultural issues, where a dominance of the lingua franca culture may occur. With this kind of linguistic and cultural dominance happening, the point needs to be raised that IC becomes even more relevant and important because Non-Native Speakers (NNS) of English may block certain features of their own cultural identity when communicating within an English lingua franca. As Crystal observes: "When a language dies, so much is lost" (2012, p. 20), and we inherit a monolingual world. 
As language promoters and professionals it is our basic practice to encourage monolingual students to learn additional languages, not just as a tool for communication but as an access route to other cultures.

Within this scenario, our study focuses on language specialists and non-language specialists. Firstly, we investigate the student language specialists' perceptions, experiences and awareness of intercultural issues and practices. Secondly, we explore the intercultural awareness of student nonspecialists and MES. Thirdly, and finally, we compare the differences between language specialists, non-language specialists and MES in regards to their levels of intercultural awareness and ICC. The main goal of the study was to identify which IC gaps exist amongst the different types of participants, and in particular the challenges that MES encountered in developing their intercultural awareness and IC.

\section{Methodology}

In this section, a description of the data collection and the methodology used for the analysis will be outlined. The method employed to conduct this research was a mixed-method approach which involves acquiring both qualitative and quantitative data from the student subjects. Data was gathered in two different stages using several tools and after being granted ethical approval from our institutional Ethics Committee. During the first stage (see Table 1 below), qualitative data was solicited respectively from student individual academic blogs and a student focus group. The participants herein were language specialists (Year Two Applied Language students learning at least two foreign languages) taking a 12-week language and technology module at the University of Limerick. Throughout the semester, each student was required to write a weekly reflective blog post about the topics explored during the lectures and activities carried out in the PC lab sessions. There was one blog post writing task dealing specifically with the IC \& ICC topics, and all students were asked to reflect upon and offer their own thoughts on various aspects of this important subject. As regards the focus group, a single cohort of students met with the two researchers who carried out a semi-structured interview where the participants could contribute freely and openly with their responses. The interviewers had several keywords/questions that they used to prompt 
the student interventions (e.g. student perceptions of IC \& ICC as language learners, evaluating the relevance of IC \& ICC for their future careers, feedback on the module and the topics covered and assessment mechanisms implemented in the course). The main objective of the semi-structured interview was to gather student opinions on IC \& ICC and also to share their perceptions and experiences regarding the importance of intercultural issues which may influence and impact upon their lives beyond the academic learning context. The interview was recorded and later transcribed for the analysis. This qualitative data allowed the further exploration of student perceptions, experiences and awareness within the ICC theme.

\begin{tabular}{|l|l|}
\hline \multicolumn{1}{|c|}{ Source } & \multicolumn{1}{|c|}{ Academic Year 2017-2018 } \\
\hline Blogs & Individual weekly blog entry $(n=70)$ \\
\hline Focus group recording & 23 minutes in duration $(n=22)$ \\
\hline
\end{tabular}

Table 1: Data gathered during the first stage of the study

In order to analyse the qualitative data, a thematic discourse analysis was adopted (Fairclough, 2013). Thematic analysis is a reliable and proven method for conducting many forms of qualitative analysis. This method includes: "identifying, analysing, organising, describing and reporting themes found within a data set", (Nowell et al. 2017:2). To establish a successful data analysis these steps were followed: familiarisation with the data; assignment of initial codes; search and examination of various themes; the definition and nomination of previously identified themes and compilation of the final report.

In the second stage of the study, we conducted two surveys of third level students at UL from a wide range of disciplines (see Figure 1 below) and nationalities (see Figure 2). Survey A ( $n=94$ ) was completed by non-language specialists and language specialists who had spent time abroad, while Survey B ( $n=141)$ was completed by non-language specialists with limited, if any, experience of working or studying abroad. Both surveys were distributed across all faculties of the university among Third and Fourth Year students, by a representative from the Students' Union. Again, 
following ethics approval from the relevant committee, this research approach proved to be successful in generating a favourable response rate from students. The data was sourced using questionnaires delivered via Survey Monkey. Both surveys included a total of 15 questions contained in several sections, namely: Participant Profile; International (or intercultural) Communication; Assessment of personal (inter)cultural awareness. Several of the questions were rating questions based on a five-point Likert scale, whilst others were multiple choice or yes-no questions. For each of the questions, students were invited to elaborate on their answers by leaving an additional comment. This allowed the researchers to explore different viewpoints. The questions were mainly focusing on two important areas: student experiences with other cultures and nationalities; self-assessment of their ability to value, evaluate and learn from their own and other cultures.

For the quantitative analysis, descriptive statistics were used, allowing us to compare figures and results between the two targeted groups. After the quantitative and qualitative data analyses, a discussion was carried out and some conclusions and recommendations were drawn from the results.

\section{Students' profile: course of study}
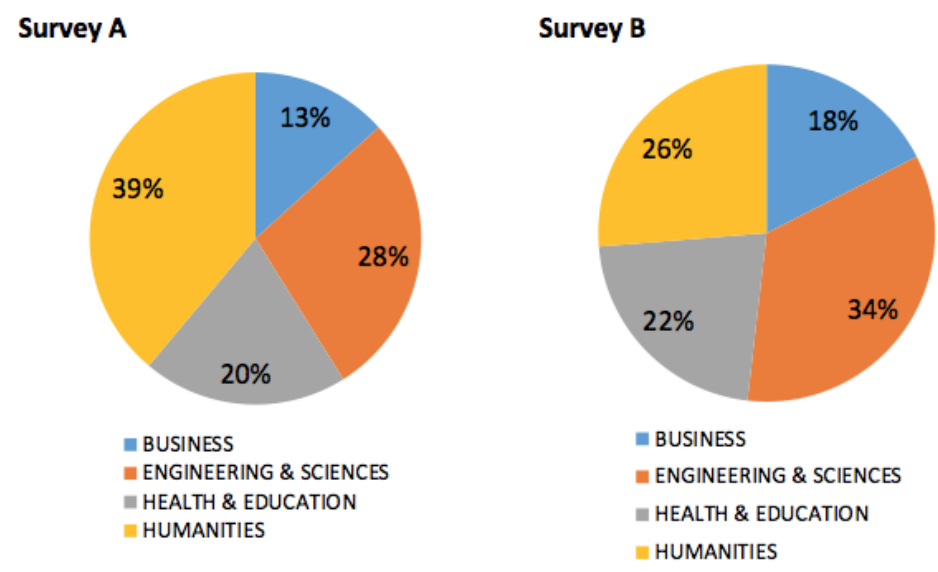

Figure 1: Disciplines of the survey's participants 


\section{Students' profile: nationality}
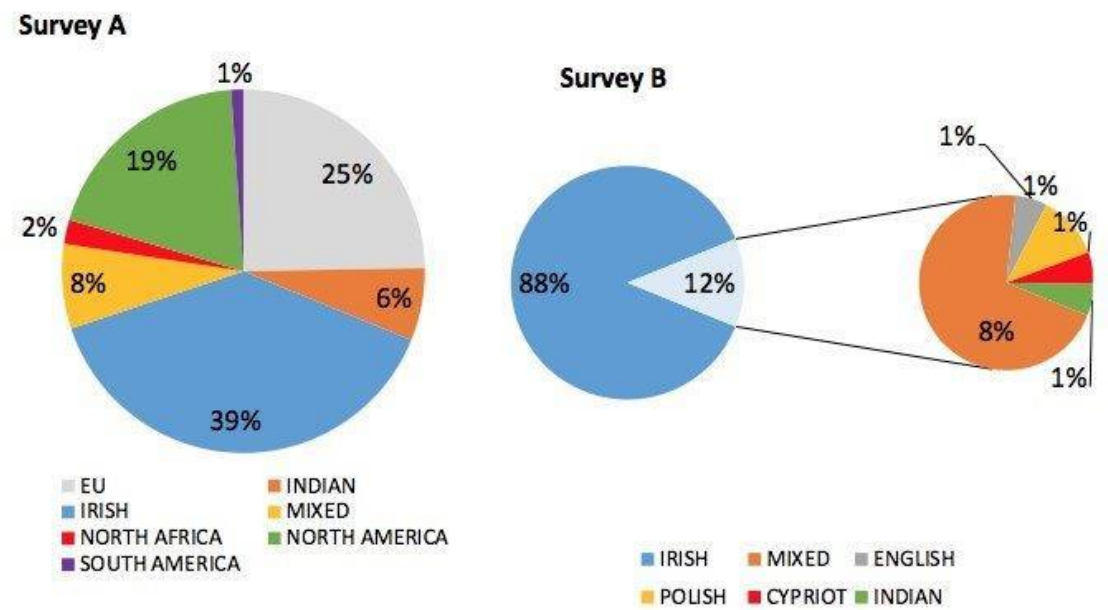

Figure 2: Nationalities of the survey's participants

\section{Data Analysis And Results}

After analysing the qualitative data previously gathered during the initial stage of this investigation, the main identified themes covered a broad range of issues, most of them significantly relevant for this study. We established two thematic categories:

1. Issues related to pedagogical practices regarding language and intercultural teaching and,

2. Issues related to ICC.

Table 2 below displays the main themes and subthemes of these two categories. However, in this article we will focus only on some of the subthemes: ICC and language development through real interactions with natives; Perception that language alone is taught in class but culture or ICC are not; Importance of learning about the target culture and developing ICC; ICC and the period abroad. This is performed in order to allow us to explore the ICC perceptions and experiences of language specialists with the ICC perceptions of non-language specialists and MES. 


\begin{tabular}{|l|l|}
\hline \multicolumn{1}{|c|}{ Pedagogical and learning practices: } & \multicolumn{1}{|c|}{ Issues related to ICC: } \\
\hline $\begin{array}{l}\text { ICC and language development through real } \\
\text { interactions with natives }\end{array}$ & Perceptions of ICC and IC \\
\hline $\begin{array}{l}\text { Perception that language alone is taught in class } \\
\text { but culture or ICC are not }\end{array}$ & ICC and the period abroad \\
\hline ICC as the element that stands out as the main \\
difference with traditional language learning & $\begin{array}{l}\text { ICC and employability: importance of and } \\
\text { different levels of the ICC required when } \\
\text { working in one's own country or working } \\
\text { and developing ICC }\end{array}$ \\
\hline $\begin{array}{l}\text { Importance of learning about the target culture } \\
\text { abroad }\end{array}$ \\
\hline
\end{tabular}

Table 2: Thematic and subtheme categories from the analysed data

The theme relating to the pedagogical and learning practices illustrates various aspects regarding the teaching of culture and ICC. The majority of the students stated that the achievement of a deep and proper understanding of another culture could only occur when interacting with Native Speakers (NSs). A typical comment was: "You may speak the language but you do not fully understand the culture until you are immersed in it and interact with it". They believed that the development of IC and ICC only takes place when they interact with NSs. It is interesting to note that students perceive such a development as taking place outside of our language classroom contexts and happening in both immersive (in the Target Language Country/-ies) and nonimmersive (on campus with NSs) environments. 
Based on the evidence found in the student quotations we are presenting below, we will argue that language specialists feel that the pedagogical practices in their specialised language programmes do not yet offer a proper training in and knowledge transfer about culture and intercultural skills. Respondents observed that language may be taught in class but not the discrete subject known as 'culture' or the necessary skills and components needed in order to develop ICC, as one student respondent declared:

"In the classroom setting I think we are learners of language. Of course we learn about aspects of the culture from literature, however this tends to be outdated. I think to be a learner of culture we have to interact with people of that culture and immerse ourselves in $i t^{\prime \prime}$

The results also made it clear that the students displayed some limitations in their understanding of ICC as they related more to the sociopragmatic elements of ICC alone: "In my opinion, ICC is essentially understanding and obeying other culture's social etiquette, norms while simultaneously being proficient in the language. Not to be confused with cultural assimilation".

In order to develop ICC, our respondents revealed a definite perceived dependency on the period spent abroad. Amongst the evidence, we found that many students thought this to be a necessity whilst others had found the experience to be operative and useful and remarked insightfully:

"By going on a 'stay abroad' period it will allow the individual to become more intuitive in the culture as every country has many cultures within that country. The most effective way for students to learn about the target language and culture is to live for a period in the country of your target language."

"The most effective way for students to learn about the target language and culture is to live for a period in the country of your target language. Studying abroad aids the development of resilience and improves the adaptive ability when transitioning into the 
working world"

"I consider language to be based on the culture of its speakers (...) Language and culture are completely intertwined and to learn a language without any communication to those within that linguistic or cultural origin would be impossible".

In sum, the language specialists typically validate their ICC when they interact with a native speaker of the Target Language, exposing a definite gap in our teaching practices. Amongst them, there was a widespread perceived dependency on the period abroad for ICC acquisition and learning of the target culture. With indirect reference to the Languages Connect Strategy, we are glad to report that after gaining some IC awareness in our language and technology module, students observed that ICC could greatly improve their employability and help them "to connect" and "to interact effectively" in diverse and multicultural environments:

"I can't put into words how beneficial ICC would be in the world of work, as every company seems to have ambitious plans to expand in this day and age, and being able to liaise with companies in foreign countries would be a very attractive trait to possess. It's one thing being able to talk to a foreign representative from a country, but imagine being able to build bonds and relationships".

In addition to the qualitative data, we can report some of the results from the quantitative data, which was collected during the second phase of the investigation. From the analysis, our results indicate that students who had previously been abroad believed that the presence of international students in their classes did not add any value or help them in preparing for their period abroad, although some participants expressed a certain 'cultural empathy' (echoes of Jones, 2010) towards their international peers (see Table 3). 


\section{Quotations that evidence development of empathy}

It didn't prepare me for going abroad per say [sic], it did make me aware of the attitude native students may have towards me and it also made me more sympathetic towards UL's own Erasmus students.

I understand how international students feel now in a new university and I will go back and be more apt to befriend international students.

There were International students in some of my lectures before going abroad although I didn't make the same effort to communicate with them beforehand as I now do.

I never really thought to interact much with international students before I went so can't say it helped but I have interacted with them a lot more since.

Table 3: Quotations from students about developing empathy

Conversely and perhaps rather unsurprisingly, students who have never been abroad did view the presence of international students in their classes as an added value, as Figure 3 indicates below. International students appear to add another perspective to the class and contribute by bringing new cultural dimensions about which Irish students may be unaware. As one student commented: "They bring a new perspective to classes and can teach us things that we could be oblivious to in Ireland". Cultural diversity exposure and global perspective in conjunction with language learning are other elements that are considered to be enhanced due to the presence of international students: "With my course especially, international students have a great impact on both language learning and opening your eyes to different cultures", with another student observing: "Diversity is important to develop our understanding of the world". Again, we can report here that some of the benefits of cultural diversity mentioned in the Languages Connect strategy are already recognised by our students. 


\section{Positive impact of international students in the classroom}

\section{- Survey B}

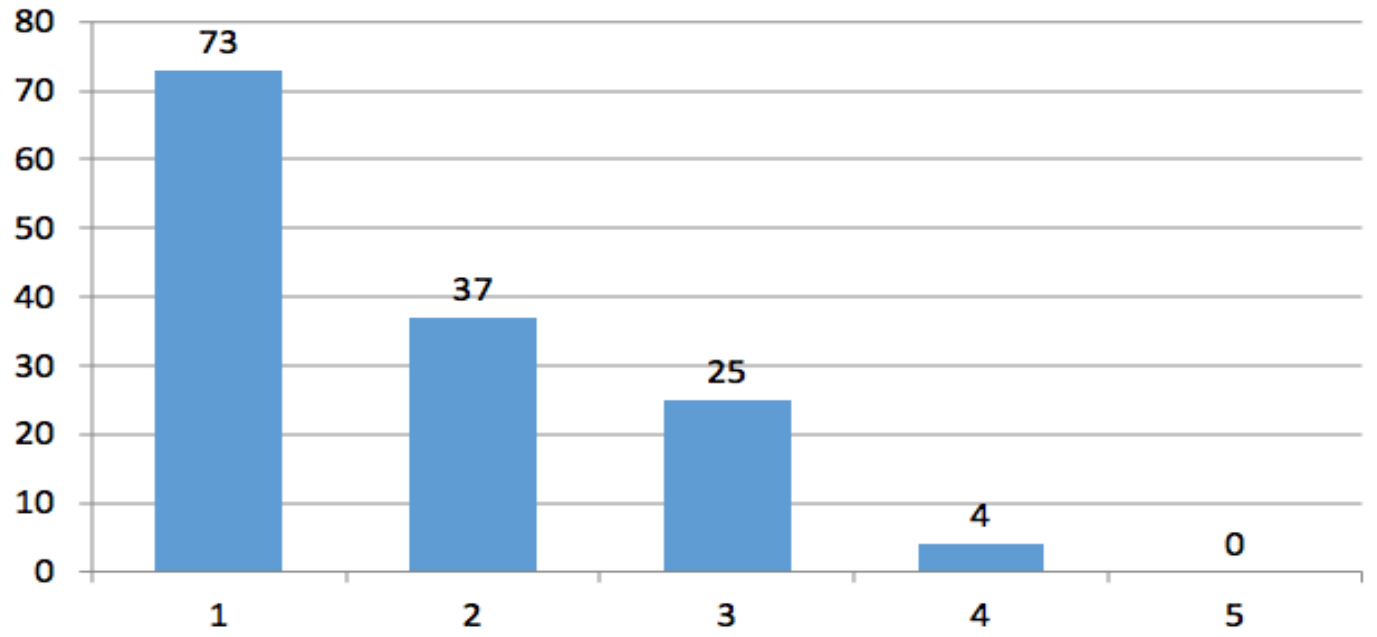

Figure 3: Perception of international students in the classroom, according to students who have never been abroad (likert scale of 1=very positive; 5=very negative)

An unexpected element that emerges from the quantitative data concerns the high similarities reported by all sets of students when asked how at ease they were when in contact with other cultures. In fact, those students (94.2\%) that have never been abroad (see Figure 4, survey B below) appear to feel equally at ease when in contact with other cultures as those students (95.7\%) that have been abroad (Figure 4, survey A). We may interpret this by arguing that all student interactions may be confined to classroom contexts or limited social exposure. Both sets of respondents may be displaying intercultural awareness here. However, when we further analyse the survey results of questions linked to assessing student intercultural skills, it becomes clear that those who have been abroad and interacted with NSs of the target culture display more features reflecting a developed intercultural competency (Figure 5). 


\section{How at ease did students feel when they were in contact with those cultures}

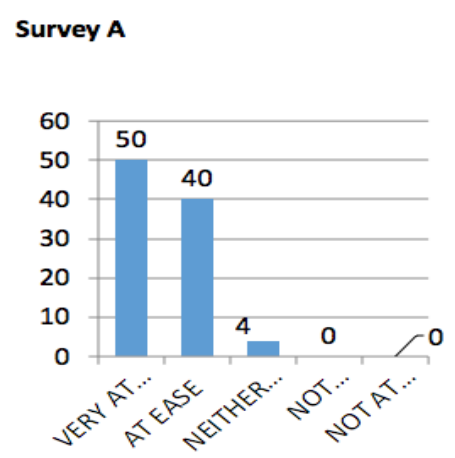

Survey B

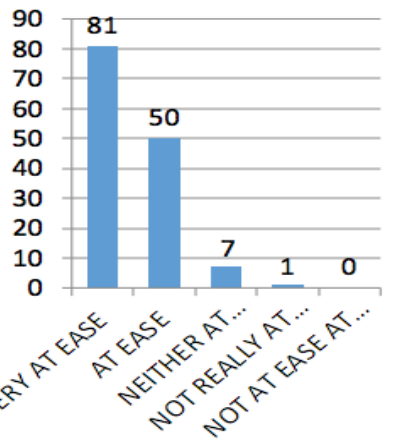

Figure 4 Student sense of ease when encountering other cultures

We may point out, for example, that flexibility, attention to nonverbal language or adaptation to socio-cultural conventions are elements that could represent a certain level of intercultural competency. The graphs presented in Figure 5 clearly show comparative values derived from both surveys and present evidence of how students who have been living abroad are more interculturally aware and display some important traits of IC development.

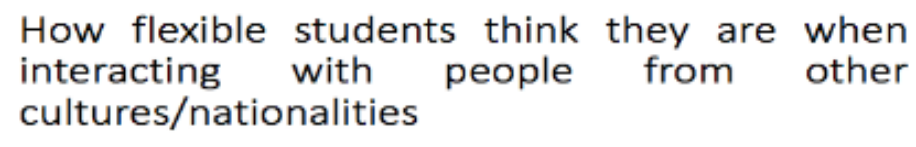

Survey A

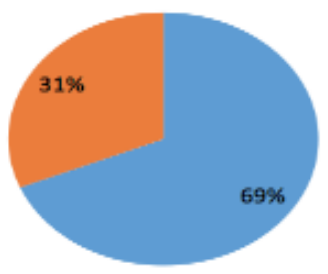

$=1=2=3=4=5$

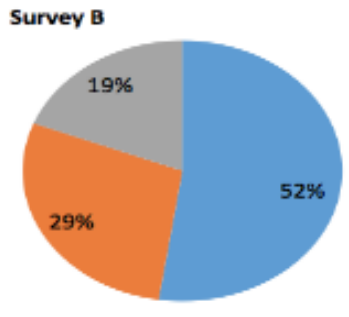

$=1=2=3=4=5$

$1=$ strongly agree $-5=$ strongly dissagree 
How easily students think they can adopt the sociocultural conventions of other cultural groups

Survey $\mathbf{A}$

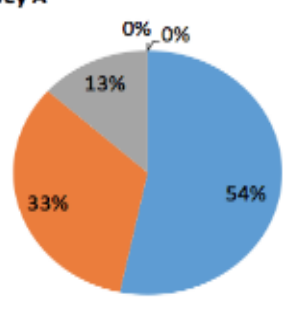

$=1=2=3=4=5$
Survey B

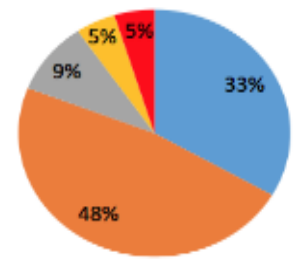

$-1=2=3=4=5$
How much attention students think they pay to the gestures used by people from other cultures

Survey $A$
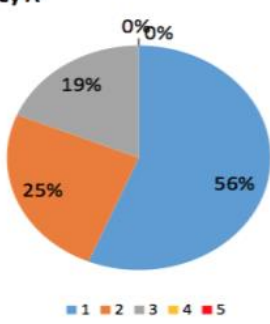

$1=$ strongly agree $-5=$ strongly disagree

1= strongly agree -5 - strongly disagree

Figure 5 Comparative values and important traits of IC development

Finally, the last issue that the data yield is related to the efficiency and effectiveness of communicating with other cultures and the avoidance of misunderstandings. Again, those students who report having spent time interacting with other cultures outside their native country are more competent at communicating proficiently and avoiding misunderstandings (see Figure 6 below).
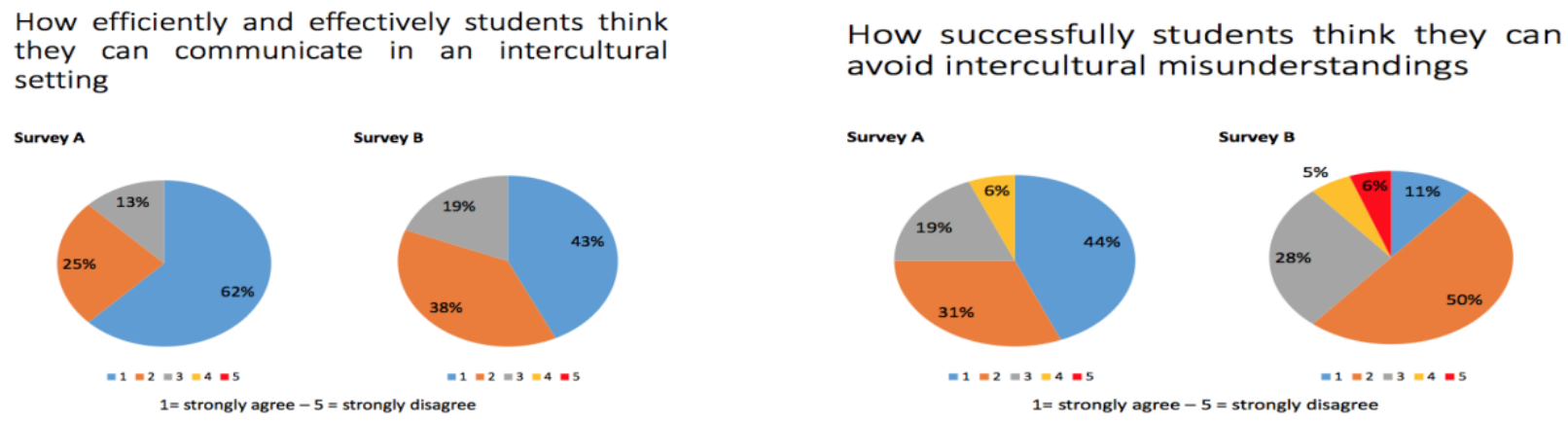

Figure 6 Comparative values of effective intercultural communication and avoidance of misunderstandings

\section{Discussion And Conclusions}

We will now discuss some of the findings from the data analysis, which will lead us to the conclusions and recommendations. It is important to bear in mind that the participants in our study have different profiles-language specialists and non-specialists, MES and those with study abroad experience-and that needs to be taken into account in this discussion in order to avoid misinterpretation and generalisation of the data. 
Commenting on the perceived dependency on the period abroad by the language specialists, it may be stated that this perception gains validation when we consider from the survey results how much those students who have not been abroad (survey B respondents) value the presence of international students in their classes. Equally, students who have been abroad - and not necessarily language specialists - show some signs of empathy development when they consider the presence of international students in their classes. Cultural empathy has been acknowledged as being one of the soft skills that one needs to develop as an intercultural speaker (Williams, 2005; Black and Duhon, 2006; Jones, 2010). Deardorff (2008) also highlights the importance of acquiring empathy, placing it as one of her important 'internal outcomes' of IC, with adaptability and flexibility being the others. The experience of having spent time abroad may have raised the intercultural awareness of the students further and initiated the development of their IC. As the Languages Connect Strategy also points out and our data supports this, exposure to cultural diversity can lead to the development of IC.

Other findings from our research present evidence of the necessity and relevance of student interactions with other cultures, be they in foreign or domestic contexts. However, it is not simply a question of sharing space or being aware of how enriching cultural diversity may be, there must be interaction. In view of our results, it is an important matter of interacting with other cultures, as also illustrated within Byram's model where one of the five savoirs reinforces how crucial interaction skills remain (Byram, Gribkova \& Starkey, 2002). The Languages Connect strategy promotes the study of languages not just from the instrumental point of view but as a route of access to other cultures. In our institution we have a large section of the student population who do not speak any foreign languages and, based on the results of our study, the mere exposure to international students-in the classroom and on the campus-does not seem to be enough to develop intercultural skills and competency. We need to address this issue if IC \& ICC are to be fostered (and if we want more language learners) and students from different cultures need to interact. Also, and despite the efforts of the European Commission to increase the levels of student mobility through the Erasmus Programme (Communiqué of European Ministers responsible for 
higher education, 2009), the percentage of students that study abroad is still relatively low, being under $10 \%$ of the European student body.

Moreover, for the $88 \%$ of our non-specialist respondents reportedly having exposure to learners from other cultures in their classroom settings, this is not sufficient motivation nor inspiration for them to pursue foreign language acquisition. As mentioned earlier, the question must be raised about the dangers of linguistic hegemony (Phillipson, 2000) and a new world order of English. Our more local concern here is mainly about how we could help MES become IC competent, and not only for increasing their employment opportunities but to ensure that our graduates become intercultural citizens who will have developed their intercultural citizenship (Byram, 2008) and will have acquired intercultural communication skills. We reiterate the point that learning a foreign language is one of the most effective and authentic ways of accessing another culture, carrying with it all of the advantages mentioned in the Languages Connect Strategy, however, there remains a distinct need to break this vicious circle of monolingual complacency, if not monolingual imperialism that continues to exist amongst our undergraduate students.

Selecting two quotations from our student data, we may be able to shed some light in the direction of breaking this circle. Intercultural awareness could be the catalyst that may motivate students to seek to know more about other cultures and foster an interest in learning other languages: "International students provide different viewpoints due to various cultures and encourage other students to learn a new language to be more involved and aware" and "When interacting with different cultures I want to know more about that culture and the only way I can really [gain] access to it is through the language".

\section{Recommendations}

Based on our conclusions, we have the following recommendations. At a local level, our language classes need to combine all the sociopragmatic elements within the process of raising intercultural awareness as well as including authentic cultural scripts in language teaching practices. We recommend increasing virtual exchanges as an integrated activity in the curricula (Murray and 
Giralt, 2019) and as an extendable and flexible activity to complement Erasmus+ or even offer the possibility of virtual mobility. These practices based on virtual exchanges should be available not just for language specialists but across all the university faculties. As well as virtual exchanges, we recommend practices in our domestic intercultural contexts with more formalised face-to-face encounters between Erasmus+, international and host institution students. As one example of this, Batardière and Jeanneau (2015) describe their successful and effective practices in face-to-face tandem exchanges between international and domestic students in a university setting.

Finally, we could implement internationalisation initiatives for staff, e.g. a series of professional development modules on topics such as 'teaching international students'. Equally, for students, we could introduce generic 'broadening modules' covering topics such as 'communicating across cultures'. These modules should be offered on a university-wide basis and not only reside within the Faculty of Arts and Humanities but in the Science, Engineering and Business faculties too.

One of the ultimate goals of a greater 'internationalisation curriculum' and producing employable global citizens requires an increased 'fraternalisation' (or 'Interculturalisation', as Jones, 2018 defines it) in order to: upgrade our own teaching practices; change current student perceptions; and ultimately facilitate the development of employable, multilingual and interculturally competent global citizens. The Irish government's Languages Connect strategy is the first formal step in this direction and it should be welcomed and applauded. We would recommend that the Strategy itself be included in our own curricula across all university disciplines, thus emphasising the importance of interculturalisation. Ultimately, however, it should become a definitive actionable government policy if it is to be more effective and bring positive linguistic, IC \& ICC benefits.

\section{References}


Angouri, J. 2014. Multilingualism in the workplace: Language practices in multilingual contexts. Multilingua. Journal of Cross-Cultural and Interlanguage Communication 33(1-2), pp. 1-9.

Batardière, M-T, \& C. Jeanneau. 2015. Facilitating a face-to-face tandem language exchange on a university campus. Studies in Self-Access Learning Journal 6(3), pp. 288-299.

Belshaw, D. 2012. What is 'digital literacy'? A Pragmatic investigation. Unpublished PhD Thesis. Durham University.

Bennett, M. 1986. A developmental approach to training for intercultural sensitivity. International Journal of Intercultural Relations 10(2), pp. 179-195.

Bennett, M. 2004. Becoming interculturally competent. In Wurzel, J. S., (ed.) Toward multiculturalism: a reader in multicultural education. Newton, MA: Intercultural Resource Corporation, pp. 62-77.

Black, H. T. and D. L. Duhon. 2006. Assessing the impact of business study abroad programs on cultural awareness and personal development. Journal of Education for Business 81(3), pp. 140-144.

Burns, A. \& C. Coffin. 2013. Analyzing English in a global context: A reader. London: Routledge.

Byram, M. 1997. Teaching and assessing intercultural communicative competence. Bristol: Multilingual Matters.

Byram, M., B. Gribkova, and H. Starkey. 2002. Developing the intercultural dimension in language teaching: A practical introduction for teachers. Strasbourg: Council of Europe.

Byram, M. 2008. From foreign language education to education for intercultural citizenship: Essays and reflections (Vol. 17). Bristol: Multilingual Matters.

Chen, G. M. and W. J. Starosta. 2006. Intercultural awareness. In Samovar, L. A., R. E. Porter \& E. R. McDaniel (eds), Intercultural communication: A reader. Belmont, CA: Thomson/Wandsworth, pp. 357-366.

Communiqué of the Conference of European Ministers Responsible for Higher Education, Leuven and Louvain-la-Neuve, 28-29 April 2009.

Crystal, D. 2012. English as a global language. Cambridge: Cambridge University Press. 
Currarini, S., J. Matheson \& F. Vega-Redondo. 2016. A simple model of homophily in social networks, European Economic Review 90, pp. 18-39.

De Wit, H. 2016. Internationalisation and the role of Online Intercultural Exchange. In O'Dowd, R., \& T. Lewis (eds), Online intercultural exchange: Policy, pedagogy, practice (Vol. 4). London: Routledge, pp. 69-82.

Deardorff, D. K. 2008. Intercultural competence: A definition, model, and implications for education abroad. In Savicki, V. (ed.), Developing intercultural competence and transformation: Theory, research, and application in international education. Sterling, VA: Stylus, pp. 32-52.

Deardorff, D. \& E. Jones. 2012. Intercultural competence: An emerging focus in international higher education. The SAGE handbook of international higher education, pp. 283-303.

Demangeot, C., N. R. Adkins, R. D. Mueller, G. R. Henderson, N. S. Ferguson, J. M. Mandiberg, \& A. J. Broderick. 2013. Toward intercultural competency in multicultural marketplaces. Journal of Public Policy \& Marketing, 32(special issue), 156-164.

Demont-Heinrich, C. 2009. Language, globalization, and the triumph of popular demand: The discourse of populism in American prestige press coverage of the global hegemony of English. The Communication Review 12(1), 20-49.

Department of Education and Skills. 2017. Languages Connect - Ireland's Strategy for Foreign Languages in Education https://www.education.ie/en/SchoolsColleges/Information/Curriculum-and-Syllabus/Foreign-LanguagesStrategy/fls languages connect strategy.pdf

Dervin, F. 2012. Cultural identity, representation and othering. In Jackson, J. (ed.) The Routledge Handbook of Language and Intercultural Communication 2, Routledge, Abingdon, Oxon, UK, pp. 181-194.

Fairclough, N. 2013. Critical discourse analysis: The critical study of language. London: Routledge. Graddol, D. 2006. English Next. Why Global English May Mean the End of 'English as a Foreign Language'. London: British Council and \& The English Company. 
Gregersen-Hermans, J. \& M. D. Pusch. 2012, How to design and assess an intercultural learning experience. In Berado, K. \& Deardorff, D. (eds.) Building Cultural Competence: Innovative Activities and Models, Stylus Publishing, Virginia, USA, pp.23-41.

Griffith, R. L., L. Wolfeld, B. K. Armon, J. Rios, \& O. L. Liu. 2016. Assessing Intercultural Competence in Higher Education: Existing Research and Future Directions. ETS Research Report Series 2016(2), pp. 1-44.

Haigh, M. \& V. A. Clifford. 2010. Widening the graduate attribute debate: a Higher education for Global citizenship. Brookes eJournal of Learning and Teaching 2(5) http://bejlt.brookes.ac.uk/paper/widening the graduate attribute debate a higher edu cation for global citize-2/

Hockly, N., G. Dudeney \& M. Pegrum. 2014. Digital literacies. London: Routledge.

Jenkins, J. 2015. Global Englishes: A resource book for students. London: Routledge.

Jones, E. 2010. 'Don't worry about the worries': Transforming lives through international volunteering. In Jones, E. (ed.), Internationalization and the Student Voice: Higher Education Perspectives. London: Routledge, pp.109-123.

Jones, E. 2018. "Internationalisation, employability and the role of languages", Keynote talk at AESLA Conference 2018, Cadiz, Spain.

Kramsch, C. 2019. "Global Citizens or Global Consumers? Reframing FL Education in the Digital Age", keynote address at the Conference, Educating the Global Citizen: International Perspectives on Foreign Language Teaching in the Digital Age, March 25th-28th, 2019, University of Munich, Ludwig-Maximilians-Universität.

Lanvers, U. \& J. A. Coleman. 2017. The UK language learning crisis in the public media: A critical analysis. The Language Learning Journal, 45(1), pp. 3-25.

Lazarsfeld, P. F. and R. K. Merton (1954). "Friendship as a social process: A substantive and methodological analysis." Freedom and control in modern society 18(1), pp. 18-66.

Maguth, B. \& J. Hilburn (eds). 2015. The state of global education: Learning with the world and its people (Vol. 1). London: Routledge. 
Millard, D. 2017. “People Like You Like Presentations Like This”, keynote speech at EuroCALL 2017 Conference, University of Southampton, August 23-26, 2017. URL: https://www.slideshare.net/hoosfoos/people-like-you-like-presentations-like-this

Morais, D. B. \& A. C. Ogden. 2011. Initial development and validation of the global citizenship scale. Journal of studies in international education 15(5), pp. 445-466.

McPherson, M., L. Smith-Lovin \& J.M. Cook. 2001. "Birds of a feather: Homophily in social networks." Annual review of sociology 27(1), pp. 415-444.

Murray, L. \& M. Giralt. 2018. Linguistic and Intercultural competencies in a globalised world: current student perceptions versus pedagogical practices. AESLA: Conference of the Spanish Society for Applied Linguistics, Cadiz, Spain.

Murray, L. \& M. Giralt. 2019. Cultivating Diversity and Intercultural Citizenship within the ERASMUS+ Virtual Exchange (EVE) Programme, guest lecture at University of Malaya, Kuala Lumpur, Malaysia, June, 2019.

Nekvapil, J. \& T. Sherman. 2018. Managing superdiversity in multinational companies. In Creese, A. \& Blackledge, A. (eds) The Routledge handbook of language and superdiversity. London: Routledge, pp. 329-344.

Nowell L. S., J. M. Norris, D. E. White \& N. J. Moules. 2017 Thematic Analysis: Striving to meet the trustworthiness criteria, The international journal of qualitative methods, 16(1), pp.1-13, available: doi: $10.1177 / 1609406917733847$

Nuffield Languages Inquiry (2000). Languages: The Next Generation: the Final Report of the Nuffield Languages Inquiry. Nuffield Foundation.

Orsini-Jones, M. \& F. Lee. 2018. Intercultural Communicative Competence for Global Citizenship: Identifying cyberpragmatic rules of engagement in telecollaboration. London: Palgrave MacMillan.

Phillipson, R. 2000. English in the new world order. Variations on a theme of linguistic imperialism and "world" English. In Ricento, T. (ed.), Ideology, politics and language policies: Focus on English, John Benjamins, Amsterdam, Holland, pp. 87-106.

Reinmoeller, P. \& N. Van Baardwijk. 2005. The link between diversity and resilience. MIT Sloan Management Review 46(4), 61. 
Schroedler, T. 2018. Value of Foreign Language Learning. Wiesbaden: Springer VS.

Sherman, T. \& M. Strubell. 2013. Multilingualism in companies: An introduction. Journal of Multilingual and Multicultural Development 34(6), pp. 511-514.

Vaara, E., J. Tienari, R. Piekkari, \& R. Säntti. 2005. Language and the circuits of power in a merging multinational corporation. Journal of management studies 42(3), pp. 595-623.

Welch D. E. \& L. S. Welch. 2017. Coping with multilingualism: Internationalization and the evolution of language strategy. Global Strategy Journal, 1-22. https://doi.org/10.1002/gsj.1191

Williams, T. R. 2005. Exploring the impact of study abroad on students' intercultural communication skills. Journal of Studies in International Education 9(4), pp. 356-371.

Witte, A. 2014. Blending Spaces. Mediating and Assessing Intercultural Competence in the L2 Classroom. Boston/Berlin: De Gruyter.

Wyburd, J. 2018. Building Capacity in UK Higher Education. In Kelly, M. (ed.) Languages after Brexit. London: Palgrave-Macmillan, pp. 173-183. 